Acta Crystallographica Section A

Foundations of Crystallography

ISSN 0108-7673

Received 15 February 2007

Accepted 15 August 2007

\section{Nexus, crystallographic computing all around the world}

\author{
Lachlan Michael David Cranswick, ${ }^{\text {a* }}$ William Bisson ${ }^{\mathrm{b}}$ and Jeremy Karl Cockcroft ${ }^{\mathrm{b}}$ \\ ${ }^{a}$ National Research Council of Canada, Chalk River Laboratories, Chalk River, Ontario K0J 1P0, \\ Canada, and ${ }^{\mathbf{b}}$ Department of Chemistry, University College London, Christopher Ingold \\ Laboratories, 20 Gordon Street, London WC1H OAJ, UK. Correspondence e-mail: \\ lachlan.cranswick@nrc.gc.ca
}

\begin{abstract}
Crystallographic Nexus CD-ROMs, containing a range of free crystallographic software for single-crystal and powder diffraction available on the Internet, have been distributed on request since 1996. The free CD is made in the form of a 'virtual Internet' with the main intent of benefiting crystallographers with inadequate Internet access. The IUCr funds an annual/biennial update which is distributed to known previous recipients. Feedback from current recipients indicates the CD is still useful. The most current IUCr-funded CD is being produced by the CCP14 project at University College London and The Royal Institution UK for distribution to the ECM 2007 and AsCA 2007 conferences.
\end{abstract}

Table 1

Approximate costs in USD for computer hardware as a function of year.

Original costs in Australian and Canadian currency have been converted into USD using February 2007 conversion rates (AUD $1=$ USD 0.77; CAD $1=$ USD 0.85).

\begin{tabular}{llll}
\hline Equipment & June 1996 & June 1997 & December 2006 \\
\hline CD writer & 1550 & 620 & 26 \\
Fast hard disk & 970 & 540 & 34 \\
Internet modem & 500 & 155 & 50 \\
& $(28 \mathrm{kB}$ baud $)$ & $(28 \mathrm{kB}$ baud $)$ & $(768 \mathrm{kB}$ DSL $)$ \\
\hline
\end{tabular}
academics and students in less technically advanced region was generally unavailable, inadequate, costly; and, if available at all, often restricted to e-mail. As computational analysis is crucial in crystallography, there was, and still is, a challenge to ensure access to a range of crystallographic analysis tools.

\section{Nexus CD creation and distribution}

To help mitigate poor Internet access for affected crystallographers and students, a free CD-ROM was initiated in mid1996 that contained a variety of crystallographic software and Internet resources. The free CD-ROM was regularly updated and air-mailed on request irrespective of the person's geographic location. The aim of the $\mathrm{CD}$ was to put relevant parts of the crystallographic Internet into a form suitable for scientists and students with poor Internet access. The CD provides recipients with modern free crystallographic tools and information for structure analysis and teaching.

Around the mid 1990's in Australia, home- and small-officebased CD writing hardware was becoming generally affordable, enabling the creation of CD-ROMs without professional assistance. For initial versions of the Nexus CD, it was a challenge using a 28000 baud modem-based link to the Internet to fill up the then massive CD-ROM space of $650 \mathrm{MB}$ with useful crystallographic material. As years progressed, with broadband Internet, more powerful computer hardware and software distributions of much larger size, the problem changed to one of $650 \mathrm{MB}$ becoming an increasingly small space in which to fit a range of crystallographic software and resources.

Current grabbing of programs and web content is performed with the program Grab-a-Site for MS-Windows 95 (Blue Squirrel, 1998), using a residential $768 \mathrm{kB}$ DSL connection and personal laptop PC computer with Intel CPU running Microsoft Windows XP. Downloading content for the CD-ROM, CD creation and burning is reliable and routine. The time and cost to create CDs has reduced considerably since the mid-1990's (Tables 1-3).

\section{Software included on the CD-ROM}

The content on the CD-ROM varies to fit within CD-ROM size constraints, with emphasis on including multiple packages that perform similar crystallographic analyses. In the 2006 version of the $\mathrm{CD}$, small-molecule single-crystal suites 
Table 2

Approximate times required to download and generate a Nexus CD-ROM image, as a function of year.

\begin{tabular}{|c|c|c|c|}
\hline & June 1996 & June 1997 & December 2006 \\
\hline $\begin{array}{l}\text { CD content download time } \\
\text { and file manipulation }\end{array}$ & $\begin{array}{l}200 \mathrm{~h}(28 \mathrm{kB} \text { modem and manual } \\
\text { download under Microsoft Windows } 3.1 \mathrm{x})\end{array}$ & $\begin{array}{l}40 \mathrm{~h} \text { (28 kB modem using Get-a-Site } \\
\text { under Microsoft Windows95) }\end{array}$ & $\begin{array}{l}4 \mathrm{~h}(768 \mathrm{kB} \text { DSL using Get-a-Site } \\
\text { for Microsoft Windows95 running } \\
\text { under Microsoft Windows XP) }\end{array}$ \\
\hline
\end{tabular}

Table 3

Approximate costs in USD and times for burning an individual Nexus CD as a function of year.

Original costs in Australian and Canadian currency have been converted into USD using February 2007 conversion rates (AUD $1=$ USD 0.77; CAD $1=$ USD 0.85)

\begin{tabular}{|c|c|c|c|}
\hline Time/Cost & June 1996 & June 1997 & December 2006 \\
\hline Writable CDs & $\begin{array}{l}\text { USD } 12 \\
\qquad(2 \times \text { writable })\end{array}$ & $\begin{array}{l}\text { USD } 7 \\
\qquad(4 \times \text { writable })\end{array}$ & $\begin{array}{l}\text { USD } 0.50 \\
\quad(48 \times \text { writable })\end{array}$ \\
\hline $\begin{array}{l}\text { Padded } \\
\text { envelopes }\end{array}$ & USD 0.77 & USD 0.77 & USD 0.85 \\
\hline Air-mail cost & USD 3.80 & USD 3.80 & USD 3.40 \\
\hline $\begin{array}{l}\text { Set-up time for } \\
\text { writing CDs }\end{array}$ & $90 \mathrm{~min}$ & $45 \mathrm{~min}$ & $2 \min$ \\
\hline $\begin{array}{l}\text { Time to write } \\
\text { each CD }\end{array}$ & 50 to $90 \mathrm{~min}$ & 25 to $50 \mathrm{~min}$ & 3 to $8 \mathrm{~min}$ \\
\hline
\end{tabular}

included Crystals, WinGX and PLATON. Single-crystal structure solvers included Crunch, DIRDIF, SuperFlip and programs available within Crystals, WinGX and PLATON. Freestanding powder indexing programs on the $\mathrm{CD}$ were Treor, Ito, Dicvol2006 and McMaille. Powder indexing suites were Crysfire, Fullprof-Winplotr and Chekcell, with powder structure-solution programs Fox and ESPOIR. A variety of Rietveld, structure drawing and utility programs were included, as well as a portion of the IUCr website including Crystallography Online. The source code within Armel Le Bail's Crystallography Source Code Museum is also included (Le Bail, 2002). A list of software on the CD-ROM is provided in Table 4.

\section{Distribution of the CD-ROM}

Numbers of CD-ROMs sent sorted by country are given in Table 5. Some institutes and departments reported further duplication of the $\mathrm{CD}$, followed by redistribution to colleagues in their institute and region.

The current procedure for generating and mailing a Nexus CD is similar to that in 1996 . On receiving a request for a CDROM, a current version of the CD is burnt and sent via airmail. Availability of the $\mathrm{CD}$ was advertised in the relevant Internet newsgroups, IUCr newsletters, conferences and by word of mouth from prior recipients. The rate at which CDs were sent to new recipients over the last ten years varied from zero to around twenty per month. Current rates at which new requests for CDs are received average around one per month.
Table 4

List of software packages included on the CD-ROM.

\begin{tabular}{|c|c|}
\hline Balls and Sticks & (Ozawa \& Kang, 2004) \\
\hline$B G M N$ & (Bergmann et al., 1999) \\
\hline$C A M E R O N$ & (Watkin et al., 1996) \\
\hline Celref & (Laugier \& Bochu, 2004) \\
\hline Chekcell & (Laugier \& Bochu, 2004) \\
\hline$C M P R$ & (Toby, 2005) \\
\hline $\operatorname{Conv} X$ & (Bowden, 2000) \\
\hline Crunch & (de Gelder et al., 1993) \\
\hline Crysfire & (Shirley, 2002) \\
\hline Crystals & (Betteridge et al., 2003) \\
\hline Dicvol2004/2006 & (Boultif \& Louer, 2004) \\
\hline$D I R D I F$ & (Beurskens et al., 1996) \\
\hline Discus & (Proffen \& Neder, 1999) \\
\hline Dispano & (Laugier \& Bochu, 2004) \\
\hline$D R A W x t l$ & (Finger et al., 2007) \\
\hline$E F L E C H / I N D E X$ & (Bergmann \& Kleeberg, 1998) \\
\hline ESPOIR & (Le Bail, 2001) \\
\hline EXPGUI & (Toby, 2001) \\
\hline Fox & (Favre-Nicolin \& Cerný, 2002) \\
\hline Fullprof & (Rodríguez-Carvajal, 2001) \\
\hline Getspec & (Altermatt \& Brown, 1987) \\
\hline Gretep & (Laugier \& Bochu, 2004) \\
\hline$G S A S$ & (Larson \& Von Dreele, 2004) \\
\hline Ideal & (Gould et al., 1988) \\
\hline Jana & (Petricek et al., 2000) \\
\hline Koalariet & (Cheary \& Coelho, 1992) \\
\hline Marching Cubes ELD & (Rohlíček \& Hušák, 2007) \\
\hline Maud & (Lutterotti et al., 1999) \\
\hline McMaille & (Le Bail, 2004) \\
\hline Orient Express & (Laugier \& Bochu, 2004) \\
\hline ORTEP3 for Windows & (Farrugia, 1997; Burnett \& Johnson, 1996) \\
\hline PLATON & $($ Spek, 2003) \\
\hline Poudrix & (Laugier \& Bochu, 2004) \\
\hline PowderCell & (Kraus \& Nolze, 1996) \\
\hline Rietan & (Izumi, 2003) \\
\hline Rietquan & (Lutterotti et al., 1998) \\
\hline SuperFlip & (Palatinus \& Chapuis, 2007) \\
\hline UnitCell & (Holland \& Redfern, 1997) \\
\hline Variable Count Time & (Madsen \& Hill, 1994) \\
\hline Wgetspec & (Laugier \& Bochu, 2004) \\
\hline $\operatorname{Win} G X$ & (Farrugia, 1999) \\
\hline WinFIT & (Krumm, 1997) \\
\hline WinPlotr & (Rodríguez-Carvajal \& Roisnel, 1998) \\
\hline Xfit & (Cheary \& Coelho, 1998) \\
\hline Xlat & (Rupp, 1988) \\
\hline
\end{tabular}

\section{Yearly distribution of an updated CD-ROM}

Since 2000, the IUCr (via the Committee for Electronic Publishing, Dissemination and Storage of Information) has funded regular annual or biennial updates of the CD-ROM, distributed via air-mail to all previous recipients. The intent has been to achieve one version per year, preferably timed to coincide with a suitable crystallographic conference to achieve extra distribution. The most recent IUCr-funded distribution was in June 2007, being produced by the CCP14 project at University College London and The Royal Institution, 
Table 5

Distribution by country of Nexus CD-ROMs distributed since 1996.

\begin{tabular}{|c|c|c|c|}
\hline Country & $\begin{array}{l}\text { Recipients } \\
\text { Nos. }\end{array}$ & Country & $\begin{array}{l}\text { Recipients } \\
\text { Nos. }\end{array}$ \\
\hline Algeria & 41 & Oman & 1 \\
\hline Argentina & 3 & Pakistan & 3 \\
\hline Australia & 5 & Peru & 19 \\
\hline Bolivia & 1 & Philippines & 1 \\
\hline Brazil & 13 & Poland & 8 \\
\hline Cameroon & 9 & Portugal & 4 \\
\hline Canada & 5 & Republic of Macedonia & 1 \\
\hline China & 41 & Romania & 9 \\
\hline Columbia & 3 & Russia/Russian Federation & 17 \\
\hline Costa Rica & 1 & Saudi Arabia & 2 \\
\hline Côte d'Ivoire & 1 & Senegal & 2 \\
\hline Croatia & 2 & Serbia & 2 \\
\hline Cuba & 7 & Singapore & 2 \\
\hline Czech Republic & 3 & Slovak Republic & 3 \\
\hline Egypt & 13 & Slovakia & 1 \\
\hline Eritrea & 1 & South Africa & 4 \\
\hline France & 13 & South Korea & 9 \\
\hline Germany & 16 & Spain & 2 \\
\hline Greece & 4 & Sri Lanka & 1 \\
\hline Hungary & 3 & Sweden & 3 \\
\hline India & 126 & Switzerland & 2 \\
\hline Indonesia & 5 & Syria & 3 \\
\hline Iran & 2 & Taiwan & 2 \\
\hline Israel & 4 & Tanzania & 1 \\
\hline Italy & 7 & Thailand & 4 \\
\hline Jamaica & 1 & Tunisia & 23 \\
\hline Japan & 5 & Turkey & 28 \\
\hline Latvia & 1 & Ukraine & 16 \\
\hline Malaysia & 7 & United Kingdom & 9 \\
\hline Mexico & 13 & USA & 27 \\
\hline Morocco & 4 & Venezuela & 4 \\
\hline Netherlands & 5 & Vietnam & 1 \\
\hline New Zealand & 3 & Yugoslavia & 3 \\
\hline Nigeria & 1 & Zimbabwe & 1 \\
\hline
\end{tabular}

London, UK. This timing was for distribution to the ECM 2007 conference in Morocco and AsCA 2007 conference in Taiwan, as well as the usual air-mailing distribution to previous recipients.

\section{Internet accessibility and CD-ROM usage}

As there has been no requirement for recipients to report usage of the CD-ROM, a questionnaire was sent in January 2007 to the e-mail addresses of CD-ROM recipients. The questions and responses are given in Table 6. Questions were multiple choice to minimize time needed to answer, with options for more elaboration if required. To encourage accurate negative responses, a preamble to the questionnaire emphasized that replies should admit to no longer requiring the CD-ROM if that was currently the case.

Of the 402 unique e-mail addresses to which the questionnaire was sent, e-mails to 121 of the addresses bounced and 43 responses were received. The number of bounced e-mails is not necessarily that surprising as one of the authors (LMDC) is on his sixth new e-mail address since 1996, previous e-mail addresses being defunct due to changes of employer, Internet Service Providers or an account being overwhelmed with junk e-mail.

Table 6

Answers and edited responses, with original questions, received via e-mail in January 2007.

The questionnaire was sent to all recipients of Crystallographic Nexus CD-ROM from 1996 to 2006. The first and second sections of the questionnaire do not sum to the 43 received sets of answers due to some respondents selecting multiple preferences.

Questions and respondent elaborations Responses

Local Internet for downloading scientific/crystallographic software is:

(a) routine and easy

(b) problematic but do-able with enough effort

(c) not practical due to problematic/low bandwidth Internet connectivity

(d) other (please elaborate)

(i) Cost is a problem here. Chinese Yuan (about 3/8 dollar) per MB

(ii) Computer centres are not willing to download the software and store in their computers

Nexus CDs are:

(a) no longer required due to good Internet links

(b) no longer required due to change of research interests

(c) Internet is adequate for software download but CDs are a convenient back-up

(d) required due to problematic Internet accessibility

(e) other (please elaborate):

(i) Internet access speed is so bad that at University levels [Nexus] CDs are a must

(ii) Internet accessing facilities are available

(iii) CDs are good for passing the information to students and other college teachers who are interested

Nexus CDs are used for (select multiple if required):

(a) providing crystallographic software for $\mathrm{PhD}$ degree research

(b) providing crystallographic software for Postdoc research

(c) providing crystallographic software to tenured academic research

(d) other research (please elaborate)

(e) providing software/resources for undergraduate teaching

( $f$ ) providing software/resources for $\mathrm{PhD} /$ postgraduate teaching

( $g$ ) providing software/resources for teaching workshops

(h) other teaching (please elaborate)

(i) X-ray diffractometer instrument is not available in our institution. So at least with this CD people can gain some sort of knowledge

(ii) CD content is made available to all research groups: from colleagues of other areas - chemistry, engineering through $\mathrm{PhD}$, MSc to training undergrad students. The $\mathrm{CD}$ format (instead of Internet) is particularly important to allow students (since their access to Internet is not always suitable) to explore and apply, or at least browse, through the latest achievements in this area. I also would like to state that this initiative was quite welcomed by the members, particularly students.

Nexus CDs are used for (select multiple if required):

(i) single-crystal diffraction

j) powder diffraction

(k) other diffraction (please elaborate)

14

21

12

2

4

21

21

27

25

2

14

24

18

othe

Of the 43 responses, powder diffraction usage was almost double that of single-crystal diffraction. The majority of respondents indicated that downloading of crystallographic software via the Internet ranged from 'problematic but doable' to 'not practical'. Of the 14 respondents that indicated downloading of crystallographic software via the Internet was 'routine and easy', 12 indicated a preference for still receiving the Nexus CDs in future as a convenient back-up of crystal- 
lographic software. 13 respondents were from India and six from China. Within India and China, responses varied from the Internet accessibility being 'routine and easy' to 'not practical'. This could indicate that difficulties with academic and student access to the Internet may involve regional issues and types of scientific facility.

\section{Conclusions}

While requests for CDs from new recipients have reduced markedly over recent years, feedback indicates Nexus CDROMs have been, and still are, a benefit for recipient crystallographers.

The following are thanked for suggestions, permissions and assistance in producing the Nexus CD-ROMs. Web content owners and custodians for permission to include material on the Nexus CD-ROM: Dr Armel Le Bail of the University of Le Mans, France; Dr Alan Hewat of ILL, Grenoble, France; Dr Howard Flack of the University of Geneva, Switzerland; and Mr Tony Sanderson of CSIRO Division of Minerals, Australia (deceased) for suggestions and encouragement of the initial versions of the CD-ROM. Dr Stephen Fletcher of CSIRO Division of Mineral Products, Melbourne, Australia (currently Professor of Inorganic Chemistry at the University of Loughborough, UK) for recommending the name 'Nexus' for the CDROM. Professor I. David Brown of McMaster University, Ontario, Canada, for assistance in distributing current versions of the CD-ROM, and comments on an initial draft of the text. Dr Richard Stephenson, previously of the CCP14 Project, University College London, UK, for arranging duplication and distribution of the 2005 batch-produced version of the $\mathrm{CD}$.

\section{References}

Altermatt, U. D. \& Brown, I. D. (1987). Acta Cryst. A43, 125-130.

Bergmann, J., Friedel, P. \& Kleeberg, K. (1999). IUCr Commission on Powder Diffraction Newsletter, No. 21, p. 5.

Bergmann, J. \& Kleeberg, K. (1998). IUCr Commission on Powder Diffraction Newsletter, No. 20, pp. 5-8.

Betteridge, P. W., Carruthers, J. R., Cooper, R. I., Prout, K. \& Watkin, D. J. (2003). J. Appl. Cryst. 36, 1487.

Beurskens, P. T., Beurskens, G., Bosman, W. P., de Gelder, R., GarciaGranda, S., Gould, R. O., Israel, R. \& Smits, J. M. M. (1996). The DIRDIF96 Program System, Technical Report of the Crystallography Laboratory, University of Nijmegen, The Netherlands.

Blue Squirrel (1998). Grab-a-Site for Windows version 3.0.14, $686 \mathrm{E}$. 8400 South Sandy, Utah, 84092, USA, http://www.bluesquirrel.com/ products/grabasite/.
Boultif, A. \& Louër, D. (2004). J. Appl. Cryst. 37, 724-731.

Bowden, M. E. (2000). IUCr Commission on Powder Diffraction Newsletter, No. 23, p. 21.

Burnett, M. N. \& Johnson, C. K. (1996). Report ORNL-6895, Oak Ridge National Laboratory, Oak Ridge, Tennessee, USA.

Butler, D. (1996). Nature (London), 380, 377-381.

Cheary, R. W. \& Coelho, A. (1992). J. Appl. Cryst. 25, 109-121.

Cheary, R. W. \& Coelho, A. A. (1998). J. Appl. Cryst. 31, 862-868.

Farrugia, L. J. (1997). J. Appl. Cryst. 30, 565.

Farrugia, L. J. (1999). J. Appl. Cryst. 32, 837-838.

Favre-Nicolin, V. \& Črný, R. (2002). J. Appl. Cryst. 35, 734-743.

Finger, L. W., Kroeker, M. \& Toby, B. H. (2007). J. Appl. Cryst. 40, 188-192.

Gelder, R. de, de Graaff, R. A. G. \& Schenk, H. (1993). Acta Cryst. A49, 287-293.

Gould, R. O., Moulden, N. \& Taylor, P. (1988). Department of Chemistry, University of Edinburgh, Scotland.

Holland, T. J. B. \& Redfern, S. A. T. (1997). Mineral. Mag. 61, 65-77.

Izumi, F. (2003). J. Ceram. Soc. Jpn, 111, 617-623.

Kraus, W. \& Nolze, G. (1996). J. Appl. Cryst. 29, 301-303.

Krumm, S. (1997). WinFit 1.2.1, Institut fur Geologie, Scholssgarten 5 , 91054 Erlangen, Germany.

Larson, A. C. \& Von Dreele, R. B. (2004). GSAS. Generalized Structure Analysis System. Manual, LAUR 86-748, Los Alamos National Laboratory, Los Alamos, NM, USA.

Laugier, J. \& Bochu, B. (2004). LMGP-Suite. Suite of Programs for the Interpretation of X-ray Experiments, ENSP/Laboratoire des Materériaux et du Génie Physique, BP 46, 38042 Saint Martin d'Hères, France.

Le Bail, A. (2001). Mater. Sci. Forum, 378-381, 65-70.

Le Bail, A. (2002). Crystallography Source Code Museum, http:// www.cristal.org/museum/.

Le Bail, A. (2004). Powder Diffr. 19, 249-254.

Lutterotti, L., Ceccato, R., Dal Maschio, R. \& Pagani, E. (1998). Mater. Sci. Forum, 278-281, 93-98.

Lutterotti, L., Matthies, S. \& Wenk, H.-R. (1999). Proceedings of the Twelfth International Conference on Textures of Materials (ICOTOM-12), Vol. 1, p. 1599.

Madsen, I. C. \& Hill, R. J. (1994). J. Appl. Cryst. 27, 385-392.

Ozawa, T. C. \& Kang, S. J. (2004). J. Appl. Cryst. 37, 679.

Palatinus, L. \& Chapuis, G. (2007). J. Appl. Cryst. 40, 786-790.

Petricek, V., Dusek, M. \& Palatinus, L. (2000). Jana2000. The Crystallographic Computing System, Institute of Physics, Praha, Czech Republic.

Proffen, Th. \& Neder, R. B. (1999). J. Appl. Cryst. 32, 838-839.

Rodríguez-Carvajal, J. (2001). IUCr Commission on Powder Diffraction Newsletter, No. 26, pp. 12-19.

Rodríguez-Carvajal, J. \& Roisnel, T. (1998). IUCr Commission on Powder Diffraction Newsletter, No. 20, pp. 35-36.

Rohlíček, J. \& Hušák, M. (2007). J. Appl. Cryst. 40, 600-601.

Rupp, B. (1988). Scr. Metall. 22, 1.

Shirley, R. (2002). The Lattice Press, 41 Guildford Park Avenue, Guildford, Surrey GU2 7NL, England.

Spek, A. L. (2003). J. Appl. Cryst. 36, 7-13.

Toby, B. H. (2001). J. Appl. Cryst. 34, 210-213.

Toby, B. H. (2005). J. Appl. Cryst. 38, 1040-1041.

Watkin, D. J., Prout, C. K. \& Pearce, L. J. (1996). CAMERON, Chemical Crystallography Laboratory, University of Oxford, Oxford, UK. 